\title{
Perceptions towards Online Counseling among University of Jordan Students
}

\author{
Adel Tannous ${ }^{1}$ \\ ${ }^{1}$ Faculty of Educational Sciences University of Jordan, Amman, Jordan \\ Correspondence: Adel Tannous1, Faculty of Educational Sciences University of Jordan, Amman, Jordan. E-mail: \\ a.tannous@ju.edu.jo
}

Received: May 27, 2017

doi:10.5539/mas.v11n12p68

Accepted: October 8, $2017 \quad$ Online Published: December 10, 2017

URL: https://doi.org/10.5539/mas.v11n12p68

\begin{abstract}
Technology and the use of internet has taken counseling service beyond the face-to-face to online counseling services. Online counseling has been available and widely used as more people are going online. Therefore this research aims to examine the perceptions of University of Jordan students toward online counseling. A sample of 210 respondents were selected to complete online questionnaire that contains two aspects of knowledge about and attitude toward online Counseling. The results of the study indicated that respondents have adequate information about the field of online counseling. However, face to face counseling was not the first preferences for most of the respondents. They have a positive attitude and a high level of preferring toward online counseling, and they believe that online counseling is an essential part of their way to deal with daily life problems. The results also indicated that social media is most effective way that help respondents to get online counseling, and it has tremendous effect on respondent's life.
\end{abstract}

Keywords: Internet based counseling, cyber-counseling, online counseling, health counseling, e-therapy

\section{Introduction}

The revolution of technology and the use of internet and its related web resources has taken counseling service beyond the face-to-face to electronic-based counseling services (Aaron et al,. 2005). Psychiatrists and counselors are turning to new way to help their patients, instead of coming to the office, they can simply register to an online counseling website, this new way of counseling is also known as e-counseling (Brown, 2011) (Chester and Glass, 2006) , cyber-counseling or tele therapy, some clients consider e-counseling as a substitute to In-office counseling (David et al., 2005) while others don't think it replaces the traditional methods, so they still visit the office even if they tried e-counseling to (Delida, 2005). This method can be done using traditional communication tools over the internet, such as: E-mails, Internet-voice calls, chat rooms, IM, and video conferences (Alleman, 2002).

The first online counselling was demonstrated between computers at Stanford and University of California (Kolog, 2014, Fang, 1972), Los Angeles in International Conference on Computer Communication (Rummell, and Joyce, 2010).. Some of the many reasons that make people register or start to use online counseling is that ecounseling is cheaper than traditional counseling, not all e-counseling specialists require insurance (Gelso, 2000)., clients can maintain their privacy by taking therapy at home instead of visiting the psychiatrist's office allowing them to take their time to organize their thoughts (Glueckauf, 2002)., the sessions can go as long as the client wishes and it can also be delayed or canceled easily and clients can also reselect their counselor (van de Luitgaarden, 2016).

Clients who prefer to stay unknown use this kind of therapy, along with young teenagers who can't get to the psychiatrist's office because they can't drive. There are plenty more who find e-counseling beneficial, such as people who cannot leave their house because of a disability, people who choose not to leave their house counselor so they can avoid "triggers" caused by the outside world and abused people who can't risk their abuser knowing about their therapy sessions. As clients find time to arrange their thought, therapists benefit from that time to carefully structure their questions (Holmes, 2004 Luitgaarden, 2016), chatting online also makes it easier for the therapist to supply his client with many websites which may help him/her case, e-counseling also makes it easier for the therapist to talk to his clients anywhere in the world, without even having to be at the same country.

Online counseling is distinguished to have some special characteristics like appropriateness, lack of social 
communication, unknown parties, distances and time frames (Jeffrey, 2005). The pre-mentioned features are associated with some positive and negative issues. Mostly, they were dealt with through providing appropriate guidelines to handle ethical and practical points (Kanz, 2001, Holmes, 2004)

Online counseling aims to help who want consultation services to identify and understand the characteristics of the same abilities and trends as Acquisition individual setting skill (Kraus and Zack, 2004; Larsen, 1998). selfdirected, which means bringing it to the degree of awareness of itself and its capabilities and understanding of the conditions and surroundings understanding, Achieve compatibility (Mallen, 2002) and adapt to the consultation recipient in order to facilitate their ability to perform various functions (Clark, 2002). Counseling help who need consultation to discover their abilities (Kraus, et. al 2004). And determine their goals and help them to draw their plans in line with their willingness (Kanz, 2001). It also aims to bring positive changes in the patterns of behavior of who need counseling towards community cultural and professional and help him discover himself and take and to take its own decisions (Fang, 2013).

There is no doubt that online counseling have multiple benefits and advantages have that led to the spread of the accelerated of consultation institutions to application (Larsen, 1998)., the benefits of online counseling as Meeting the needs of those who cannot come for consultation inside consultant building or live too far away from it (Mallenand Vogel, 2002), representation of online counseling of the means of continuous learning and lifelong learning (Clark, and Stone, 2002), expansion of the large capacity of who need online counseling compared to the potential limited in this area, Speeding up the information technology used in the development online counseling (Fang, 2013), and enrich his roles and his creativity in this area and the using of computer information systems with renewed high potentials (Lin et al., 2013)

There are many essential elements of online counseling such as the contact form which consists of four basic elements: consulting provider and who receive counseling (Lewis, and Coursol, 2007), information and communication channel that is divide between face to face counseling and online counseling (Rochlen, et al., 2004). Online counseling consists of the following elements: Consulting provider "counselor" (Shaw and Shaw, 2006). It is a people who design the contents of online counseling on the internet and explains the knowledge and contact with any one need counseling by contacting methods (Rochlen et al., 2004), Online counseling content: the information and knowledge that are the content of the scientific material that interacts with who receive counseling and counselor, Consultation interface (Rummell, Cand Joyce, 2010): The means that will allow the interaction between who need counseling and counselor via the Internet on one hand and between who receive counseling and the content of material on the other hand by using contacting methods (Rockwell et al., 1999) Counseling receiver: a person who requests counseling in the vicinity of the connection by communication interface (Sampson et al., 1997)

There are many Requirements for Transformation from face to face to online counseling and Difference between online counseling and Face to face counseling (Stofle, 2001); In comparing online counseling to Face to face counseling it has many benefits such as online counseling Gives an opportunity for various segments of society from housewives and workers in factories, counseling the fact that integrated with the work (Suler, 2000). Ease of updated counseling material submitted electronically (Skinner, and Latchford, 2006). Online counseling provides freedom to communicate with the consultor provider at any time and ask questions that he wants her interrogation is done through various means such as e-mail and chat rooms (Sampson, 2000). Also counseling online may be received any place and is not committed to a particular location (Suler, et al, 2001). But in Face to face counselingthe patient receives counseling Face to face counseling in traditional way at the same time and same place (Tate and Wing 2003), it is required to come to the consulting building (Tai, 2005). It defines the communication with the consulter with a time limit and takes some of the recipients of counseling the opportunity to ask questions because the time for all is not available (Yager, 2001, Yager, 2003).

This study conducted under the general theme of Jordanian University students' perceptions toward online counseling. The overall purpose is to scrutinize their knowledge about and attitudes toward online counseling, the focus is on the frequency of using internet and online counseling, material and devices used to reach online counseling and the effect of using online counseling on their life.

\section{Related work}

In 2005, Mallen, along with others, applied the practical points of e-counseling, with its Technology, ethical issues, observation, training and matters related to suitability and competency. They studied online therapy's benefits and boundaries and offered guidelines for all kinds of clients and specialists. They also made clear that it was necessary to discuss the skills and parts related to online therapy, and that may be done by using examples of synchronouschats' sessions. In Bogo 2013, an examination tool to validate the competency of both professionals and trainees 
in cyber-counseling, this method was called (COSCE) which is Cyber-Counseling Objective Structured Clinical Exam, the aspects which were tested in regards of the COSCE are, interior coherence, interline accuracy and interrater reliability. They used traditional group assessment methods and using the analysis assigned to the exploratory agent to assess the coherence of the construction. According to Bambling and his colleagues (2008) ecounseling is a separate self-dependent service and works as a helping factor to the other services. Synchronous and asynchronous chats can be conducted in a virtual world, and through that, counseling process takes place.

A case study of empirical kind was concluded by Luitgaarden and der Tier in 2016, the targets of the study were social workers and service users, the purpose was to establish a relationship between the two parties via chat rooms, the study was based on analyzing two conversations from the chats they conducted and an interview from each one of the Sample in the research, making it a sum of five interviews and ten conversations.

In 2005, Vogel and Mallen further discussed the matter of importance of clarifying how helpful the services that people find online for mental health and behaviors, in providing them with psycho-education and methods to help themselves and help others, also in offering direct therapy and counseling, they also studied a lot of insights provided by reactants, such as their beliefs on how appropriate these online services are for people underserved, or on the priority that should be given to online counseling and whether it should come first or second in the area of counseling.

A study conducted by Granello 2000 and Krieger 2004, illustrated that demonstrating the hesitancy in applying elearning methods on educating and practicing counseling, and may be achieved through practicing foresights and the dubitable research that backed up the efficiency of online education.

Researchers in 2016, such as Omeje and Egeonu illustrated that the universities in Nigeria and especially the southern Eastern ones, have facilities which are specialized in e-counseling, and this was in a study for federal universities' undergraduate students. The therapists and students also use this method (e-counseling) to help with their career info distribution. Some conclusions were made based on the results of the study. More standards were set by Barnett in 2005, as he actually studied the process of e-counseling, such as distributing information in a more effective way, improving the training process, having more access to programs which are associated with innovation, and the growing support efforts.

Tai Chang made an article in 2005 that also illustrated what was recommended in regards to e-counseling's practice and study, the study extended to the journal issued in November of 2005 called "The Counseling Psychologist", this journal focuses on giving the priority to researching and practicing psycho-education, parties mutually helping each other and helping themselves. The study suggests that the number of American people searching the web to educate, help and support themselves on a psychological level, is a lot bigger than the number of those looking for e-counseling by another individual. This article aimed at supporting the huge number of people in America and abroad to create their own agenda related to practicing and researching information about mental health and how to help themselves and others mentally. Another study was conducted by Delida Sanchez in 2005 to see how appropriate e-counseling may be for the people who live in underserved areas. She provided methods on how to help and serve those people to get online psycho-education, she also illustrates those methods where the internet is nowadays helpful for this kind of counseling.

\section{Methodology}

\subsection{Sample of the Study}

The Sample in this study are students in bachelor and master degree from Faculty of Educational Sciences in the University of Jordan within the range of (18-40) years old. The original sample on which the study tools were applied consisted of 210 as shown in table 1 .

Table 1. Distribution the sample of the study

\begin{tabular}{lll}
\hline Demographic Variables & & percentage \\
\hline Gender & Male & $89.5 \%$ \\
\cline { 2 - 3 } & Female & $10.5 \%$ \\
\hline \multirow{2}{*}{ Age } & $18-20$ & $72.43 \%$ \\
\cline { 2 - 3 } & $20-25$ & $4.8 \%$ \\
\cline { 2 - 3 } & $26-30$ & $5.65 \%$ \\
\cline { 2 - 3 } & $30-40$ & $4.3 \%$ \\
\hline Qualification & Bachelor & $83.8 \%$ \\
\hline
\end{tabular}




\begin{tabular}{lll}
\hline & Master degree & $16.2 \%$ \\
\hline Scientific specialization & Counseling and Special Education & $76.7 \%$ \\
\hline & Other & $23.3 \%$ \\
\hline
\end{tabular}

The demographic characteristics of the sample are listed in Table 1. It can be observed that $89.5 \%$ of the Sample were females and $10.5 \%$ were males and $72.43 \%$ were Less than 20 years, $4.8 \%$ of the Sample were between 20 and 25 years, and $5.65 \%$ were between 20 and 25 years, $4.3 \%$ were above the age of 30 years. Around $83.8 \%$ of the sample in Bachelor degree qualification and $16.2 \%$ in Master degree. It can be observed that $76.7 \%$ of the sample were studying in counseling and special Education

\subsection{Data Collection and Analysis Method}

The data collected using online questionnaire. According to Chisnall (1997) the non-response is a critical limitation of a research, and in order to reduce a non-response rate, the researcher was available at the time of disseminating the online questionnaire to the sample. 210 questionnaires were distributed on a sample of graduate and undergraduate students

The questionnaire was reviewed by the researchers at the faculty of educational Sciences at Jordan University. The questionnaire contains Part I that was used to collect the demographic date. Part II have questions that intend to measure the knowledge about and attitude of online counseling. After collected the data from the sample of the study, SPSS v.11.5 was used for data analysis statically, reliability analysis and regression analysis were applied in statistical analysis. Testing the questionnaire reliability was using Cranach alpha. A value with more than 0.7 means a good consistency. The value of Cronbach's alpha for all paragraphs are higher than 0.7 which indicate an acceptable values of research testing, the reliability in the $70 \%$ range was acceptable and those who were over $80 \%$ were good (Sekaran, 2003).

\section{Results}

The results indicated that $91 \%$ of the sample of the study used internet in daily base. A highly percentage of $82 \%$ of the sample use online counseling in daily base. hence, $48.2 \%$ had used online counseling more than ten times, $21.9 \%$ had used online counseling between 4 to 10 times and only $29.9 \%$ had used online counseling between 1 to 3 times, as shown in table 2 .

Table 2. Frequency of using internet and online counseling

\begin{tabular}{|c|c|c|c|c|}
\hline How many time do you use the internet & Daily & Weekly & Monthly & Yearly \\
\hline & $91 \%$ & $4.7 \%$ & $3.3 \%$ & $0.9 \%$ \\
\hline \multirow[t]{2}{*}{ Have you ever used online counseling } & Yes & No & & \\
\hline & $82 \%$ & $18 \%$ & & \\
\hline \multirow[t]{2}{*}{ How many times do you use online counseling } & $1-3$ times & $4-10$ & More than 10 times & \\
\hline & $29.9 \%$ & $21.9 \%$ & $48.2 \%$ & \\
\hline
\end{tabular}

The results showed that the most common devices used to reach online counseling are Mobile, Computer and laptop devices and the most used method of communication in online counseling are websites and social media with a possible rate of $52.6 \%$ as shown in table 3 and table 4 :

Table 3. Devices used for online counseling

\begin{tabular}{llll}
\hline Computer and laptop & Mobile & Landline telephone & Others \\
\hline 33.9 & $54.6 \%$ & $10.3 \%$ & $1.2 \%$ \\
\hline
\end{tabular}


Table 4. Method of communication used for online counseling

\begin{tabular}{llllll}
\hline $\begin{array}{l}\text { Method of communication } \\
\text { reach online counseling }\end{array}$ & used to & $\begin{array}{l}\text { E- } \\
\text { mail }\end{array}$ & $\begin{array}{l}\text { Voice over internet } \\
\text { protocol }\end{array}$ & $\begin{array}{l}\text { Video } \\
\text { conferencing }\end{array}$ & $\begin{array}{l}\text { Websites and } \\
\text { Social media }\end{array}$ \\
\hline & $27.3 \%$ & $14.8 \%$ & $5.3 \%$ & $52.6 \%$ \\
\hline
\end{tabular}

Most of the sample of this study have positive attitudes toward online counseling and they feel comfortable to use it when they face trouble or need help the result indicated that $72.3 \%$ of the sample see that online counseling is better than face to face counseling and $83.6 \%$ feel more comfortable when they use it as shown in table 5 .

Table 5. Attitudes toward online counseling

\begin{tabular}{|c|c|c|c|}
\hline No. & Item & Yes & No \\
\hline 1 & Online counseling is better than face to face counseling & $72.3 \%$ & $27.7 \%$ \\
\hline 2 & I feel more comfortable with online counseling than face to face counseling & $83.6 \%$ & $16.4 \%$ \\
\hline 3 & In the future, would you use online counseling when needed & $75.5 \%$ & $24.5 \%$ \\
\hline 4 & $\begin{array}{l}\text { Do you think it is important to have a short training program to explain how } \\
\text { counseling can be helpful to you before using online counseling }\end{array}$ & $85 \%$ & $15 \%$ \\
\hline 5 & Do you believe online counseling can be as effective as face to face counseling & $65 \%$ & $35 \%$ \\
\hline 6 & $\begin{array}{l}\text { Do you think it is important for online counselor to meet you in-person before } \\
\text { providing online counseling services }\end{array}$ & $28.8 \%$ & $71.2 \%$ \\
\hline 7 & $\begin{array}{l}\text { Do you know anyone (other than yourself) who has used online counseling or } \\
\text { therapy }\end{array}$ & $61.7 \%$ & $38.3 \%$ \\
\hline 8 & Do you recommend other people to use online counseling & $82.9 \%$ & $17.1 \%$ \\
\hline 9 & Online counseling will help me to discover more about myself & $67.2 \%$ & $32.8 \%$ \\
\hline 10 & $\begin{array}{l}\text { If you have personal problem do you prefer to go to online counselor more than face } \\
\text { to face counselor }\end{array}$ & $84.4 \%$ & $15.6 \%$ \\
\hline 11 & $\begin{array}{l}\text { If you have emotional problem do you prefer to go to online counselor more than face } \\
\text { to face counselor }\end{array}$ & $82.1 \%$ & $17.9 \%$ \\
\hline
\end{tabular}

Results in table 5 showed that highly percentage of $75.5 \%$ of the sample will use online counseling when needed. The results of this study also indicate that there are statistically $85 \%$ think it is important to have a short training program to explain how online counseling can be helpful to them before they use online counseling, Result showed that large percentage of $65 \%$ believe that online counseling can be as effective as face to face counseling, $28.8 \%$ think it is important for an online counseling provider to meet with in-person before providing online counseling services. The percentage of the sample about knowing anyone else who has used online counseling or therapy was $61.7 \%$ and the major percentage of $82.9 \%$ recommend other people to use online counseling. The majority of the sample prefers to use online counselor to solve both their personal and emotional problems

The results shows that online counseling is available and easily to be accessed from everywhere anytime they want by using the internet with percentage of $85 \%$. Therefore the majority of the Sample prefer to rely on online counseling to solve their daily life problems and feel that the information they get from online counseling is useful and is very helpful for them as shown in table 6 .

Table 6. knowledge about online counseling

\begin{tabular}{llll}
\hline No. & Item & YES & NO \\
\hline 1 & Online counseling is available and easy to access & $85 \%$ & $15 \%$ \\
2 & Do you prefer to rely on online counseling to solve your daily life problems & $68.6 \%$ & $31.4 \%$ \\
& & \\
3 & You feel that the information that you get from online counseling is useful & $59.5 \%$ & $40.5 \%$ \\
4 & Online counseling reduce time wasted in face to face counseling & $75.5 \%$ & $24.5 \%$ \\
\hline
\end{tabular}




\begin{tabular}{|c|c|c|c|}
\hline 5 & Online counseling have privacy. & $72.7 \%$ & $27.3 \%$ \\
\hline 6 & All online counseling resources are trusted (websites, & $44.7 \%$ & $55.3 \%$ \\
\hline 7 & $\begin{array}{l}\text { When using online counseling there is no need for attendees to counseling sessions } \\
\text { through the process in contrast to traditional way in face to face counseling }\end{array}$ & $76.4 \%$ & $23.6 \%$ \\
\hline 8 & $\begin{array}{l}\text { Online counseling provide different types of counseling techniques which is not } \\
\text { possible in face to face counseling }\end{array}$ & $84.3 \%$ & $15.7 \%$ \\
\hline 9 & The online counseling provide an easier method to get counseling & $73.2 \%$ & $26.8 \%$ \\
\hline 10 & provide many counselling services that patient need & $84.9 \%$ & $15.1 \%$ \\
\hline 11 & $\begin{array}{l}\text { Online counseling contributes in solving the problems facing people who need } \\
\text { counseling and shy to use the traditional face to face counseling }\end{array}$ & $80.8 \%$ & $19.2 \%$ \\
\hline 12 & $\begin{array}{l}\text { Do you think online counseling is an effective way to deal with psychiatric disorders } \\
\text { such as depression, emotional distress ...etc. }\end{array}$ & $14.3 \%$ & $85.7 \%$ \\
\hline 13 & $\begin{array}{l}\text { Do you think online counseling is an effective way to deal with behavioral problem } \\
\text { such as problem solving, increasing awareness, self-control ....etc. }\end{array}$ & $63.4 \%$ & $36.6 \%$ \\
\hline
\end{tabular}

It can be observed from table 6 that $75.5 \%$ of the Sample find that using online counseling reduce time wasted. It also provide privacy; so the students have the ability to express themselves without any boundary through the online and internet tools which is considered private. Despite the high rate of privacy the results showed that $55.3 \%$ see that not all online counseling resources are trusted as matter of hacking or information leak that may happen. Most of the responses indicated that when using online counseling there is no need for attendees to counseling sessions and it also provide different types of counseling techniques which is not possible in face to face counseling The results showed high rate from the Sample whom believed that online counseling may provide easier way to get the services of counseling to meet the patient needs, furthermore the results showed that online counseling contributes in solving the problems facing who need counseling with rate of $80.8 \%$.

Most sample results showed that online counseling is an effective way to deal with behavioral problem such as problem solving, increasing awareness, and self-control but not with psychiatric disorders.

Table 7. The effect of online counseling

\begin{tabular}{llllll}
\hline $\begin{array}{l}\text { How you describe the } \\
\text { effect of online } \\
\text { counseling in your life }\end{array}$ & $\begin{array}{l}\text { No } \\
\text { effect }\end{array}$ & $\begin{array}{l}\text { Rare } \\
\text { positive } \\
\text { effect }\end{array}$ & $\begin{array}{l}\text { Moderate } \\
\text { positive } \\
\text { effect }\end{array}$ & $\begin{array}{l}\text { Strong } \\
\text { positive } \\
\text { effect }\end{array}$ & $\begin{array}{l}\text { Very strong } \\
\text { positive effect }\end{array}$ \\
\hline & $7.6 \%$ & $11.8 \%$ & $30.4 \%$ & $42.1 \%$ & $8.1 \%$ \\
\hline
\end{tabular}

The results of the study indicated that using online counseling have strong positive effect on their life with possible rate of $42.3 \%$ while $7.6 \%$ mentioned that online counseling has no effect in their life as shown in table 7 .

\section{Discussion}

The purpose of this study was to explore Jordanian University students' knowledge and attitudes toward online counseling. The results of the study indicated that students had adequate information about the field of online counseling. If they were to choose between face to face and on line counseling their preference would be on line counseling because of their worries about face to face counseling. As a Jordanian, in our culture face to face counseling is related to the concept of psychiatric disorders which is not accepted-regardless of their severity or type. Singh (2012) suggests that there are many reasons that make people do not utilize face to face counseling such as shame, stigma, and accessibility. As a result, some people in Jordan never reach face to face counseling services for cultural reason.

The findings also showed that the Sample demonstrated a high level of preferring online counseling. According to Richards and Vigan (2013) online counseling can have a similar impact and is capable of replicating the facilitative conditions as face-to-face counseling. In Jordan online counseling is becoming more popular and viable form of counseling with advances in Information and communications technology (ICT), so the available and easily access internet in Jordan through mobile and wireless network make it easy to get online services and resources, which helped user's to reach online counseling very fast and get response any time of the day. According to Zamani and 
her colleagues (2010) online counseling has been available and widely used as more users are going online, and it is important to note that more people will continue to look to the internet as a resource for dealing with their problems

The results showed that social media is most effective way that help people to get online counseling due to the variety of information that exists in social media which explained why the Sample in this study rely on internet to get online assistant in their personal problems which is difficult sometimes to ask counselors face to face. And the other reason was if the participant could not attend some of the sessions due to some reasons like getting sick, going abroad, or severe bad conditions, so they prefer online counseling in order not to miss the sessions.

The most interesting finding in this study that most of the sample showed positive attitude and tremendous effect in their life by using online counseling. This results similar to the results of the study that conducted by Zamani et.al. (2010) Bato \&Marcial, (2016).

On the other hand, most of the sample assumed that not all problems can be resolve by online counseling they thought that online counseling is best with problem solving, time management, increasing awareness, self-control and addiction. Almost the entire sample believed that online counseling is not proper with severe problems like mood or psychiatric disorder. And they had concerns about the loss of nonverbal, ethics, trust, confidentiality, security, reliability, technical malfunctions, pacing and empathy, so the lack of perceived privacy and security during online counseling sessions and the fear of being caught while conducting online sessions were the main concerns reported by the sample.

According to Teh and his colleagues (2014) The attitude towards online counseling (vis-à-vis face-to-face counseling) was generally positive and the sample in his study indicated openness to conducting online counseling, but they still consider face-to-face counseling more effective than online counseling.

\section{Conclusion}

This study showed good knowledge about online counseling and the respondent believe that online counseling is essential part of their way to deal with daily life problems. So they think that taking training program in online counseling will be helpful and assist to deal with effective and behavioral difficulties and it would enhance the opportunities to get professional help. Therefore, the study recommends further research to explore the differences between men's and women's perceptions of online counseling; in addition researchers may want to address the evidence of discomfort toward face to face counseling services than online counseling services. Additional areas of research should be considered is to understand how attitudes toward online counseling related to some variables like age, gender, socioeconomic status, marital status.

\section{References}

Aaron, B., Rochlen , David, L., Vogel, \& Michael, J. M. (2005). The Practical Aspects of Online Counseling, Ethics, Training, Technology, and Competency. The Counseling Psychologist November, 1(33), 776-818.

Alleman, J. R. (2002). Online counseling: The internet and mental health treatment. Psychotherapy, 39, 199-209

Bambling, M., King, R., Reid, W., \& Wegner, K. (2008). Online counselling: The experience of counsellors providing synchronous single-session counselling to young people. Counselling and Psychotherapy Research, 8(2), 110-116. https://doi.org/10.1080/1473314080205501

Brown, G. W. (2011). Social work and social services web sites. Retrieved November 1, 2017, from http://gwbweb.wustl.edu/resources/pages/socialservicesresourcesintro.aspx

Chester, A., \& Glass, C. (2006). Online counseling: A descriptive analysis of therapy services on the Internet.

Chisnall, P. M. (1997). Marketing Research. McGraw-Hill Publishing Company.

Clark, M. A., \& Stone, C. B. (2002). Clicking with Students: Using Online Assignments in Counselor Education Courses. Journal of Technology in Counseling, 2(2), n2.

David, L. V., \& Michael, J. M. (2005). Online Counseling A Need for Discovery. The Counseling Psychologist November, 1(33), 910-921.

Delida Sanchez-Page (2005). The Online-Counseling Debate A View Toward the Underserved. The Counseling Psychologist November, 1(33), 891-899.

Fang, L., Bogo, M., Mishna, F., Murphy, L., Gibson, M. F., Griffiths, V., \& Regehr, G. (2013). Development and initial evaluation of the cyber-counseling objective structured clinical examination (COSCE). Research on Social Work Practice, 23(1), 81-94. 
Gelso, C. J., \& Lent, R. W. (2000). Scientific training and scholarly productivity: The person, the training environment, and their interaction.

Glueckauf, R. L., Fritz, S. P., Ecklund-Johnson, E. P., Liss, H. J., Dages, P., \& Carney, P. (2002). Videoconferencing-based family counseling for rural teenagers with epilepsy: Phase 1 findings. Rehabilitation Psychology, 47(1), 49.

Holmes, L., \&Ainsworth, M. (2004). The future of online counseling. In R. Kraus, J. Zack,\&G.Stricker (Eds.), Online counseling: A handbook for mental health professionals (pp. 257-269). San Diego, CA: Academic Press.

Ivey, A., \& Ivey, M. (2007). Intentional Interviewing and Counseling 6th Ed. Thomson.

Jeffrey E. Barnett , (2005), Online Counseling New Entity, New Challenges The Counseling Psychologist 33: 872-880 Loyola College in Maryland, Independent Practice, Arnold, Maryland

Kanz, J. E. (2001). Clinical-supervision.com: Issues in the provision of online upervision. Professional Psychology: Research and Practice, 32, 415-420.

Kanz, J. E. (2001). Clinical-supervision.com: Issues in the provision of online supervision. Professional Psychology: Research and Practice, 32, 415-420.

Kolog, E. A., Sutinen, E., \& Vanhalakka-Ruoho, M. (2014). E-counselling implementation: Students' life stories and counselling technologies in perspective. International Journal of Education and Development using Information and Communication Technology, 10(3), 32.

Kraus, R., \& Zack, J. S. (2004). The business aspects of online counseling. In R. Kraus, J. Zack, \& G. Stricker (Eds.), Online counseling: A handbook for mental health professionals (pp.145-160). San Diego, CA: Academic Press.

Kraus, R., Zack, J., \&Stricker, G. (Eds.). (2004). online counseling: A handbook for mental health professionals. San Diego, CA: Academic Press.

Larsen, L. M. (1998). The social cognitive model of counselor training. The Counseling Psychologist, 26, 219273.

Lewis, J., \& Coursol, D. (2007). Addressing career issues online: Perceptions of counselor education professionals. Journal of Employment Counseling, 44(4), 146.

Lin, F., Marion, B., Faye, M., Lawrence, M., Margaret, F., Gibson. V. G., \& Glenn, R. (2013s). Development and Initial Evaluation of the Cyber-Counseling Objective Structured Clinical Examination (COSCE), Research on Social Work Practice January 1, 2013

Mallen, M. J., \& Vogel, D. L. (2002, August). Working toward online counselor training: Dynamics of process and assessment. In AB Rochlen (Chair), Appeal and relative efficacy of online counseling: Preliminary findings. Symposium conducted at the annual convention of the American Psychological Association, Chicago.

Omeje, J., Ukamaka, E., Justina, \& Chika, E. D. (2016). Utilization of E-Counseling in Career Information Dissemination among Undergraduates of Federal Universities in South East Nigeria. SAGE Open. 6 https://doi.org/10.1177/2158244016655586

Richards, D., \& Viganó, N. (2013). Online Counseling: A Narrative and Critical Review of the Literature. Journal of Clinical Psychology, 69(9), 994-1011.

Rochlen, A. B., Beretvas, S. N., \& Zack, J. S. (2004). The online and face-to-face counseling attitudes scales: A validation study. Measurement and Evaluation in Counseling and Development, 37(2), 95-111.

Rochlen, A. B., Zack, J. S., \& Speyer, C. (2004). Online therapy: Review of relevant definitions, debates, and current empirical support. Journal of clinical psychology, 60(3), 269-283.

Rockwell, S., Schauer, S., Fritz, S., \& Marx, D. (1999). Incentives and obstacles influencing HE faculty and administrators to teach via distance. Online Journal of Distance Learning Administration, 2.

Rummell, C. M., \& Joyce, N. R. (2010). So wat do u want to work on 2 day? The ethical implications of online counseling. Ethics \& Behavior, 20(6), 482-496.

Sampson, Jr., J. P. (2000). Using the internet to enhance testing in counseling. Journal of Counseling \& Development, 78, 348-356.

Sampson, Jr., J. P., Kolodinsky, R. W., \&Greeno, B. P. (1997). Counseling on the information highway: Future 
possibilities and potential problems. Journal of Counseling \& Development, 75, 203-212.

Sekaran, U. (2003). Research methods for business: A skill building approach. USA: John Wiley \& sons, Inc.

Sekaran, Uma (2003). Research methods for business: A skill building, Fourth Edition, John Wiley \& Sons Inc.

Shaw, H.E., \& Shaw, S.F., 2006. Critical Ethical Issues in Online Counseling: Assessing Current Practices With on Ethical Intent Checklist. Journal of Counseling and Development, 84, 41-53.

Skinner, A. E. G., \& Latchford, G. (2006). Attitudes to counseling via the Internet: Acomparison between in-person counseling clients and internet support groupusers. Counselling and Psychotherapy Research, 6(3), 158-163.

Stofle, G. S. (2001). Choosing an online therapist: A step-by-step guide to finding professional help on the web. White Hat Communications. 2001

Suler, J. (2000). Psychotherapy in cyberspace: A 5-dimensional model of online and computer-mediated psychotherapy. Cyber Psychology and Behavior, 3, 151-160.

Suler, J., Barak, A., Chechele, P., Fenichel, M., Hsiung, R., Maguire, J., Meunier, V., Stofle, G., Tucker-Ladd, C., Vardell, M. \& Walker-Schmucker, W. (2001). Assessing a person's suitability for online therapy. CyberPsychology\& Behavior, 4, 675-679.

Tai, C. (2005). Online Counseling Prioritizing Psychoeducation, Self-Help, and Mutual Help for Counseling Psychology Research and Practice. The Counseling Psychologist, 33, 881-89.

Tate, J., \& Wing (2003). Effects of internet behavioral counseling on weight loss in adults at risk for type 2 diabetes: A randomized trial. Journal of the American Medical Association, 289(14), 1833-1836.

van de Luitgaarden, G., \& van der Tier, M. (2016). Establishing working relationships in online social work. Journal of Social Work, 1468017316654347.

Wantz, R. A., Tromski, D. M., Mortsolf, C. J., Yoxtheimer, G., Brill, S., \& Cole, A. (2004). Incorporating distance learning into counselor education programs: A research study. In J. W. Bloom \& G. R. Walz (Ed.), Cybercounseling and Cyberlearning: An Encore (pp.327-342). Greensboro, NC: CAPS Press.

Wardell S. 2008, History of online counselling. Retrieved July 8, 2017, from http://ezinearticles.com/?Historythof-Online-Counseling-and-Child-Development\&id=1049584

Yager, J. (2001). E-mail as a therapeutic adjunct in the outpatient treatment of anorexia nervosa: Illustrative case material and discussion of the issues. International Journal of Eating Disorders, 29, 125-138.

Yager, J. (2003). Monitoring patients with eating disorders by using e-mail as an adjunct to clinical activities. Psychiatric Services, 54(12), 1586-1588.

Ybarra, M. L., \& Eaton, W. W. (2005). Internet-based mental health interventions. Mental Health Services Research, 7(2), 75-87.

Zack, J. S. (2008). How sturdy is that digital couch? Legal considerations for mental health professionals whodeliver clinical services via the Internet. Journal of Technology in Human Services, 26(2/4), 333-359.

Zainah, A. Z., Rohany, N., \& Fatimah, Y. (2010). Perceptions towards online counseling among counselors in Malaysia. Procedia Social and Behavioral Sciences, 5(2010) 585-589, 1877-0428 (C) 2010 Published by Elsevier Ltd. https://doi.org/10.1016/j.sbspro.2010.07.146

\section{Copyrights}

Copyright for this article is retained by the author(s), with first publication rights granted to the journal.

This is an open-access article distributed under the terms and conditions of the Creative Commons Attribution license (http://creativecommons.org/licenses/by/4.0/). 